\title{
RUNX2 and WWOX genes as molecular biomarkers and candidates for targeted therapy in Egyptian patients with primary conventional osteosarcoma
}

\author{
Abeer A. Bahnassy ${ }^{1 *}$, Eman Abdelzaher ${ }^{2}$, Rania Gaber², Gamal Elhosseiny ${ }^{3}$, Awad Abdel Moniem A. Rafalla ${ }^{4}$,
} Abdel-rahman N. Zekri ${ }^{5}$, Ahmad El-Bastawisi ${ }^{6}$, Hend F. Yousif ${ }^{1}$ and Layla Kamal Younis ${ }^{2}$

\begin{abstract}
Background: The conventional osteosarcoma (OS) is the commonest primary malignant, bone tumor with complex genomic profiles and poor survival. Runt-related transcription factor 2 (RUNX2) and WW domain containing oxidoreductase (WWOX) genes are implicated in normal osteogenesis as well as in the development of primary conventional OS.

Methods: We retrospectively assessed protein and RNA expression of the RUNX2 and WWOX genes by quantitative real time PCR (qPCR) and immunohistochemistry $(\mathrm{IHC})$ in 80 cases of primary OS and 20 normal control (NC) subjects. Proteins and RNA expression levels of both genes were correlated to clinico-pathological features of the patients, progression free and overall survival (PFS\& OS) rates.

Results: In OS, RUNX2 protein was detected in 72/80 (90\%) cases compared to 4/20 (20\%) NC samples $(p .<0.001)$ and RUNX2-RNA was up regulated (up to $103.2 \mathrm{folds}$ ) in 60/80 (75\%) $(p=0.01)$. WWOX protein and RNA (up to 7.2 folds) were detected in all NC samples but in 24/80 (30\%) and 20/80 (20\%) OS cases; respectively ( $p .<0.001$ for each). The concordance between the RNA and protein expressions for RUNX2 and WWOX was significantly high ( $X \_$trend $\wedge$ $2=6.33 ; p=0.012$ and $X \_t r e n d \wedge 2=19, p<0.001$; respectively). A significant inverse relation existed between RUNX2 and WWOX RNA and protein $(p=0.032, p=0.008)$. There was significant correlation between RUNX2 RNA/protein, high tumor grade and stage ( $p=<0.001$; each); RUNX2 RNA and male gender, tumor site and metastasis ( $p=0.007,0.041,0.003$; respectively). WWOX protein associated significantly with advanced stage and metastasis ( $p=0.001 \& 0.024$; respectively) and WWOX RNA associated with metastasis $(p=0.003)$.

Conclusions: RUNX2 and WWOX play opposing roles in the development and progression of OS. They could be used as sensitive prognostic biomarkers for OS patients and RUNX2 represents a promising candidate for targeted therapy.
\end{abstract}

Keywords: Osteosarcoma, RUNX2, WWOX, Prognosis

\footnotetext{
* Correspondence: chaya2000@hotmail.com

${ }^{1}$ Tissue Culture and Cytogenetics Unit, Pathology Department, National

Cancer Institute, Cairo University, Fom El Khalig, Cairo 11796, Egypt

Full list of author information is available at the end of the article
} 


\section{Background}

Osteosarcoma (OS) is the most common primary malignant, non-hematopoietic, bone tumor worldwide. It represents $55 \%$ of childhood and adolescent malignant bone tumors in the United States [1, 2]. According to the National Cancer Institute Registry in Egypt, OS represents the most common primary malignant bone tumor in constituting $47.75 \%$, of the cases followed by Ewing's sarcoma (17.57\%), chondrosarcoma (14.86\%) and NonHodgkin lymphoma (9.01\%) (NCI) [3]. It is also one of the significant causes of morbidity and mortality, especially in the young age group [1]. The etiology of OS is not well known yet and the tumors are usually heterogeneous with complex genomic aberrations and rearrangements. In spite of the recent improvements in the treatment modalities of OS including neoadjuvant or adjuvant chemotherapy and radiotherapy, the 5 year-survival is still poor (25-30\%), especially for patients with metastasis, [4, 5]. Therefore, Studying the molecular pathogenesis of OS is highly required for better understanding of tumor biology, to identify molecular prognostic and predictive biomarkers as well as for better selection of genes that could be used as candidates for targeted therapy $[6,7]$.

The Runt-related transcription factor 2 (RUNX2) and the WW domain containing oxidoreductase (WWOX) are two important genes that have recently been linked to the development and progression of OS $[8,9]$. RUNX2 gene is located at chromosome 6p12-2. It is one of the transcriptional regulators of osteogenesis, it is responsible for the terminal osteoblastic differentiation and it also triggers the expression of major bone matrix protein genes during the early phase of osteoblastic differentiation $[10,11]$. It has been shown that, the RUNX2 protein exerts its oncogenic effects through regulation of various genes and pathways which are implicated in tumorigenesis, especially in the regulation of apoptosis [12]. Overexpression of RUNX2-RNA and protein were detected in OS cases, as well as in many other tumor types with poor prognostic impact $[7,9]$.

The WWOX gene occupies an active fragile site (FRA16D) which is located at the $16 \mathrm{q} 23.3 \pm 24.1$ region. It codes for a protein, which contains two N-terminal WW domains and a central short-chain dehydrogenase/ reductase domain [13]. The WWOX protein plays an important role in the maturation of osteoprogenitor cells and in regulating their proliferation during bone development [14]. WWOX is considered a tumor suppressor gene, which is involved in the regulation of apoptosis and the interaction between the neoplastic cells and the extracellular matrix $[15,16]$. Therefore, loss of $W W O X$ expression as a consequence of genetic and epigenetic aberrations has been associated with poor prognosis and an aggressive phenotype in many tumor types [13].
The interplay between RUNX2 and WWOX genes was previously highlighted. It was found that the contribution of WWOX gene to bone formation is partially related to its regulation of RUNX2 activity [17]. Moreover, during the pathogenesis of tumors, WWOX gene exerts its regulatory effect on the signaling network through the interaction of its first WW protein domain with some transcription factors and signal transduction proteins including RUNX2, p73, Ap $2 \alpha, A p 2 \gamma$ and ErbB4 $[18,19]$. Therefore, we sought to assess, the contribution of aberrant RUNX2 and WWOX genes expressions to the development and progression of conventional OS in a group of patients from Egypt through correlating their RNA and protein expression levels to the standard clinic-pathological prognostic factors, response to treatment and survival rates.

\section{Methods}

\section{Patients and tissue specimens}

Formalin-fixed paraffin-embedded (FFPE) tissue blocks for 80 well-characterized conventional OS patients who were diagnosed and treated in the National Cancer Institute (NCI), Cairo University and the Faculty of Medicine, Alexandria University Hospitals, during the period from 2008 to 2013 were collected from the Surgical Pathology Departments of the two centers. Cases were selected according to the following criteria: 1) treatment naive patients with no previous neoadjuvant chemotherapy 2) adequacy of representative tumor tissues in the tumor blocks and 3) the availability of relevant clinicopathological and follow up data of the patients. All cases were diagnosed, graded and staged according to the WHO criteria for grading and staging of OS [20]. Twenty five, FFPE tissue blocks of normal bone biopsies, obtained from non-pathologically fractured bones matched for the age and sex with the OS patients, were also included in the study as a control group (CG). The most representative paraffin blocks were identified, hematoxylin and eosin- stained slides for the tumor samples were examined microscopically to confirm the diagnosis, determine the tumor: normal tissues ratio and to choose the proper tumor block. Only cases with $>75 \%$ representative neoplastic cells in the sections were included in the study to avoid the neutralizing effect of a high non-neoplastic component in tumor sections. From each representative paraffin block, $4 \mu \mathrm{m}$ thick sections (two sections) were cut onto positive charged slides and used for the assessment of RUNX2 and WWOX proteins expression by IHC and another $5 \mu \mathrm{m}$ thick sections (7 sections) were cut into a sterile, plastic, $2 \mathrm{ml}$ Eppindorff tube for RNA extraction and quantitative real time polymerase chain reaction (qPCR). Relevant clinico-pathological and follow-up data of the patients were obtained from the patients' records in the Clinical Oncology and the Nuclear Medicine 
Departments, Alexandria Faculty of Medicine, and the $\mathrm{NCI}$, Cairo, Egypt. The ethical committees of the two Centers approved the study protocol, which was performed according to the 2011 Declaration of Helsinki.

\section{2-Management of patients}

Pretreatment assessment of the OS patients included complete medical history, physical examination and histological examination of hematoxylin and eosin- stained slides from the tumor masses. Further assessment included ECOG performance status, lactate dehydrogenase (LDH), alkaline phosphatase (ALP), complete blood count (CBC) with differential and full biochemical panel, including liver and renal function tests. Radiological evaluation included local MRI of the primary and a computerized tomography $(\mathrm{CT})$ scan of the chest. Additional radiological imaging such as bone scan was done when indicated and imaging was repeated every 6 weeks during treatment in the neoadjuvant or metastatic settings. Evaluation was carried out according to modified RECIST criteria every 6 weeks (in case of metastatic disease). Posttreatment evaluation and follow up included medical history and physical examination, CBC and chemistry with local MRI of the primary and CT chest every 3 months. The standard treatment for all OS patients included wide excision or metastasectomy for operable cases with first line neoadjuvant/adjuvant chemotherapy using either Cisplatin $100 \mathrm{mg} / \mathrm{m} 2$ IV D1/Doxorubicin $25 \mathrm{mg} / \mathrm{m} 2 /$ day D1-D3 every 21 days for up to 6 cycles or Doxoruici/ Cisplatin/Holoxan/high dose Methotrexate. Second line therapy was given to relapsed, refractory or metastatic patients using IV Gemcitabine $675 \mathrm{mg} / \mathrm{m} 2$ (Days 1 and 8) and Docetaxel 75-100 mg/m2 IV (Day 8) every 3 weeks for up to 13 cycles (median 4 cycles). Post operative radiotherapy (RT) was considered in patients with unresectable disease (60-70 Gy) or in patients with positive resection margins (55Gy with 9-13 Gy boost to microscopic or gross disease).

\section{3-Immunohistochemistry (IHC)}

Avidin-Biotin-Peroxidase Complex (ABC) methodology was used. Briefly, the slides were de-paraffinized in xylene followed by rehydration in a series of graded ethanol. Endogenous peroxidase was blocked with $0.3 \%$ $\mathrm{H} 2 \mathrm{O} 2$ and retrieval was performed with $10 \mathrm{mM}$ citrate buffer pH6.0. Tissue sections were incubated overnight at $4{ }^{\circ} \mathrm{C}$, in a humid chamber, with the primary mouse monoclonal RUNX2 antibody (27-K, sc-101145, Santa Cruz Biotechnology, Inc., USA, dilution 1:50); and the rabbit polyclonal anti-WWOX antibody (ab33248, Abcam Inc., USA, dilution 1:100). The reaction was visualized by the UltraVision Detection System, Thermo Scientific, USA and the sections were then counterstained with Hematoxylin.
Negative and positive controls (placenta for RUNX2 and skin for $W W O X)$ were included in each run [21].

\section{4- Scoring of IHC results}

Slides were examined microscopically using Leica microscope (TC Lab, NCI). The expression levels of RUNX2 (nuclear) and WWOX (cytoplasmic) proteins were evaluated using a scoring system based on the staining intensity score multiplied by the staining extent score. The extent of staining was determined according to the percentage of stained cells as follows: $0 \%$ positively- stained cells (score 0 ), $1-10 \%$ (score 1), $>10-25 \%$ (score 2), $>25-$ $50 \%$ (score 3 ), $>50-75 \%$ (score 4 ) and $>75 \%$ positivelystained cells (score 5 ). The staining intensity was scored as follows: no staining (0), mild (1), moderate (2) and intense (score 3). For statistical purposes, the final scores were categorized into two groups: negative $(0-1)$ and positive (2-15) [22].

\section{5-RNA extraction and quantitative real-time PCR (qPCR)}

The total RNA was extracted from the tumor and the normal tissues sections using the RNeasy Mini Kit (Qiagen, Milan, Italy) and the quality of the extracted RNA was assessed by spectrophotometry. RNA was dissolved in diethyl pyrocarbonate-treated water containing $10 \mathrm{mmol} / \mathrm{l}$ of $\mathrm{MgCl} 2$ and incubated with $100 \mu \mathrm{g} / \mathrm{ml}$ of RNase-free DNaseI for $30 \mathrm{~min}$ at $37{ }^{\circ} \mathrm{C}$ to eliminate the contaminating DNA. The reaction was stopped by heating at $95{ }^{\circ} \mathrm{C}$ for 5 min after the addition of EDTA to a final concentration of $30 \mathrm{mmol} / \mathrm{l}$ and then RNA was retro-transcribed using iScriptTM cDNA Synthesis Kit (Bio-Rad, Milano, Italy). The qRT-PCR analysis was performed in a final volume of $25 \mu \mathrm{l}$ with a SYBR Green PCR Master Mix using $1 \mu \mathrm{l} \mathrm{cDNA}$ and $400 \mathrm{nM}$ of predesigned RUNX2 primer (Hs_RUNX2_1_SG QuantiTect primer assay (249900), Qiagen, Hilden, Germany) for RUNX2 gene in stratagene MAX3000P (Applied Biosystems, Inc., Foster City, CA, USA). For WWOX gene, TaqMan PCR Master Mix using Rotor- gene Q (Qiagen, Hilden, Germany) was used with $1 \mu \mathrm{l} \mathrm{cDNA}$ and $400 \mathrm{nM}$ of predesigned WWOX hydrolysis probe (Hs_WWOX_QF_1 QuantiFast probe assay (243132), Qiagen, Hilden, Germany). All steps were done according to manufacturer's instructions. For all tumor and normal bone samples, the qPCR assays were carried out in triplicates.

\section{6-Interpretation of the GPCR results}

the mean cycle threshold $\left(\mathrm{C}_{\mathrm{T}}\right.$ value) was calculated and used to determine the delta $\mathrm{CT}(\Delta \mathrm{CT})$ for each sample as follows: $\Delta C T=C_{T}$ for the gene of interest- $C_{T}$ of the internal control gene $(G A D P H)$. Then the delta delta $\mathrm{CT}$ $(\Delta \Delta \mathrm{CT})$ was calculated as follows: $\Delta \Delta \mathrm{CT}=(\Delta \mathrm{CT}$ for sample A - $\Delta$ CT for sample B), where sample A is the tumor and sample B is the calibrator (normal bone). For 
the statistical analysis, the $\Delta \Delta C T$ was used and then the data were expressed as relative expression units [23].

\section{7-Statistical analysis}

Data were analyzed using the statistical package for social science (SPSS 20). Qualitative data were described using number and percent, the association was tested using Chisquare test; if more than $20 \%$ of the cells have expected count less than 5; correction was conducted using Firsher's Exact test or Monte Carlo correction. The distributions of quantitative variables were tested for normality using Kolmogorov-Smirnov test, which revealed significant deviation from normality, and described using mean, median and standard deviation (SD). Mann-Whitney $(U)$ and Kruskal-Wallis $(H)$ tests were used to compare between two groups and more than two groups respectively. Spearman's rho $(\rho)$ correlation was used to test the relation between quantitative or qualitative ordinal variables. Significance test results were quoted as two-tailed probabilities, and judged at the 5\% level. Association of relevant clinico-pathological data, RUNX2 and WWOX expressions with progression free survival (PFS) or OS was analyzed using the log-rank test, Kaplan-Meier plot, and Cox proportional hazards regression models. $p<0.05$ was considered statistically significant. The multivariate analysis included clinicopathologic factors that had $p<0.10$.

\section{Results}

\section{Clinicopathological data of the patients}

The ages of the patients ranged from 15 to 57 years (median: 21 years), 52 were males and 28 were females (M:F ratio $=1.9: 1)$, all of them were chemotherapy-naïve. In the control group (CG), the ages ranged from 17 to 60 years (median: 19 years) with M: F ratio 2:1. Relevant clinicopathological features of the patients are illustrated in Tables 1 and 2.

\section{RUNX2 and WWOX protein expressions}

The expression levels of WWOX and RUNX2 in normal bones are illustrated in Fig. 1. In the OS group, 72 (90\%) out of the 80 cases assessed were positive for RUNX2 protein overexpression with a median staining score of 13 (Min.-Max. $=0-15,95 \%$ CI $=53.3,100)$ compared to $4 / 20$ cases only (20\%) for the control group ( $95 \% \mathrm{CI}=70,100)$ with a median staining score of 5 (Min.-Max. $=0-8)$. The difference in the expression level of $R U N X 2$ protein between cases and control subjects was statistically significant $(U=3.5, p .<0.001)$ (Fig. 2a-c). On the other hand, WWOX protein expression was detected in all the control samples $(100 \%$; $95 \% \mathrm{CI}=0,100)$ with a median staining score of 7 (Min.-Max. $=4-10)$ but in 24/80 (30\%) OS cases only. Fifty six cases showed either reduced or/lost WWOX protein expression $(70 \%)(95 \% \mathrm{CI}=54.5,100)$. The median staining score for OS cases was zero
Table 1 The relation between WWOX (protein and RNA) expressions and the clinicopathological features of the patients

\begin{tabular}{|c|c|c|c|c|}
\hline \multirow[t]{3}{*}{ Clinical features } & \multicolumn{4}{|c|}{ Aberrant WWOX expression } \\
\hline & \multicolumn{2}{|c|}{$\begin{array}{l}\text { Reduced or lost protein } \\
(56)^{b}\end{array}$} & \multicolumn{2}{|c|}{$\begin{array}{l}\text { Reduced or lost RNA } \\
(60)^{c}\end{array}$} \\
\hline & No. (\%) & $P$. value & No. (\%) & $P$ value \\
\hline \multicolumn{5}{|l|}{ Gender } \\
\hline Males (52) & $40(76.9)$ & & $38(73.1)$ & 0.588 \\
\hline Females (28) & $16(57.1)$ & 0.066 & $22(78.6)$ & \\
\hline \multicolumn{5}{|l|}{ Age (median) } \\
\hline$<21$ years $(40)$ & $32(80)$ & & $30(50)$ & 1.0 \\
\hline$\geq 21$ years $(40)$ & $24(60)$ & 0.051 & $30(50)$ & \\
\hline \multicolumn{5}{|l|}{ Site } \\
\hline Femur (48) & $34(70.8)$ & & $35(72.9)$ & \\
\hline Tibia (20) & $12(60)$ & 0.371 & $15(75)$ & 0.571 \\
\hline Humerus (12) & $10(83.3)$ & & $10(83.3)$ & \\
\hline \multicolumn{5}{|l|}{ Tumor Grade } \\
\hline $2(16)$ & $9(56.3)$ & & $10(62.5)$ & \\
\hline $3(64)$ & $47(73.4)$ & 0.180 & $50(78.1)$ & 0.197 \\
\hline \multicolumn{5}{|l|}{ pTNM Stage } \\
\hline I, II (44) & $24(54.5)$ & 0.001 & $32(72.7)$ & 0.604 \\
\hline III, IV (36) & 32 (88.9) & & $28(77.8)$ & \\
\hline \multicolumn{5}{|l|}{ Metastasis } \\
\hline Present (20) & $18(90)$ & $0.024^{a}$ & $20(100)$ & 0.003 \\
\hline Absent (60) & $38(63.3)$ & & $40(66.7)$ & \\
\hline
\end{tabular}

${ }^{\text {a Significant }}{ }^{\text {\$B Borderline significance (using intensity score) }}$

${ }^{\mathrm{b}}$ Normal WWOX protein expression: $24{ }^{\mathrm{C}}$ Normal WWOX RNA expression: 20

(Min.-Max. =0-6) (Fig. 3a-c). The difference between patients and control groups was statistically significant $(U=3.5, p .<0.001)$. A significantly negative correlation was present between $W W O X$ and RUNX2 protein expressions $(\mathrm{U}=-0.578, p=0.008)$.

\section{RUNX2 and WWOX-RNA expression}

RUNX2-RNA expression was up-regulated (up to 103.2 folds) in $64 / 80(80 \%)$ OS cases compared to $3 / 20(15 \%)$ of the control group $(p<0.001)$ (Fig. $2 \mathrm{~d}-\mathrm{f})$. WWOX gene RNA expression was down-regulated (reduced or lost) in $60 / 80(75 \%)$ cases and up-regulated in 20 cases (25\%, up to 7.2 folds, $95 \% \mathrm{CI}=54.5,100$ ) (Figs. 3 and 4). The concordance in the results of RNA and protein expressions for both genes was significantly high $(6.33 ; p .=0.012$ and $19 ; p .<0.001$, respectively). The difference between OS patients and the control group for both genes, was statistically significant $\left(p_{0}<0.01\right)$. The concordance between RNA and protein expressions for RUNX2 and WWOX was significantly high $\left(\mathrm{X} \_\right.$trend $^{\wedge} 2=6.33 ; p=0.012$ and X_trend ${ }^{\wedge} 2=19, p<0.001$; respectively). 
Table 2 The relation between RUNX2 (protein and RNA) expressions and the clinicopathological features of the patients

\begin{tabular}{|c|c|c|c|c|}
\hline \multirow[t]{3}{*}{ Clinical features } & \multicolumn{4}{|c|}{$\underline{R U N X 2 \text { expression }}$} \\
\hline & \multicolumn{2}{|c|}{$\begin{array}{l}\text { RUNX2 protein expression } \\
(72 / 80)\end{array}$} & \multicolumn{2}{|c|}{$\begin{array}{l}\text { RUNX2 -RNA expression } \\
(60 / 80)\end{array}$} \\
\hline & No. (\%) & $P$ value & No. (\%) & $P$ value \\
\hline \multicolumn{5}{|l|}{ Gender } \\
\hline Males (52) & $48(92.3)$ & & $44(84.6)$ & \\
\hline Females (28) & $24(85.7)$ & 0.348 & $16(57.1)$ & 0.007 \\
\hline \multicolumn{5}{|l|}{ Age (median) } \\
\hline$<21$ years $(40)$ & $40(100)$ & & $32(80)$ & \\
\hline$\geq 21$ years $(40)$ & $32(80)$ & 0.005 & $28(70)$ & 0.302 \\
\hline \multicolumn{5}{|l|}{ Site } \\
\hline Femur (48) & $44(91.7)$ & & $36(75)$ & \\
\hline Tibia (20) & $16(80)$ & & $12(60)$ & \\
\hline Humerus (12) & $12(100)$ & 0.232 & $12(100)$ & 0.041 \\
\hline \multicolumn{5}{|l|}{ Tumor Grade } \\
\hline $2(16)$ & $8(50)$ & & $4(25)$ & \\
\hline $3(64)$ & $64(100)$ & $<0.001^{*}$ & $56(87.5)$ & $<0.001^{*}$ \\
\hline \multicolumn{5}{|l|}{ pTNM Stage } \\
\hline I, II (44) & $36(81.8)$ & & $24(54.5)$ & \\
\hline III, IV (36) & $36(100)$ & 0.007 & $36(100)$ & $<0.001^{*}$ \\
\hline \multicolumn{5}{|l|}{ Metastasis } \\
\hline Present (20) & $20(100)$ & & $20(100)$ & \\
\hline Absent (60) & $52(86.7)$ & $0.085^{\$}$ & $40(66.7)$ & 0.003 \\
\hline
\end{tabular}

*Significant ${ }^{\$}$ Borderline significance (using intensity score)

\section{Correlation between patients characteristics and markers expression}

Significant correlations were found between increased RUNX2 expression (RNA and protein) and high tumor grade $(p .=0.032)$, between RUNX2 RNA and the TNM stage $(p .=0.01)$, as well as between RUNX2 protein and high incidence of metastasis using the intensity scoring system $(p .=0.02)$. WWOX-RNA expression correlated significantly with high tumor grade and the incidence of metastasis $(p=0.032)$, whereas $W W O X$ - protein correlated significantly with the incidence of metastasis $(p .=0.04)$. A borderline significance was present between WWOXprotein expression and the grade of the tumor $(p .=0.05)$ (Tables 1 and 2).

\section{5-Survival correlations}

During the follow up period (range $=18-72$ months, $M=45$ months, $S D=38.18), 32$ patients $(20 \%)$ showed local recurrence, 40 (25\%) showed distant metastasis, and $32(20 \%)$ patients succumbed to the disease (relapsed). The PFS time ranged from 6 to 72 months with an estimated mean survival time of 56 months $(95 \% \mathrm{CI}=46.6,65.4)$ and the overall survival ranged from 20 to 96 months with an estimated mean survival time of 72 months $(95 \% \mathrm{CI}=46.6$, 65.4). Kaplan-Meier plots showed that OS associated significantly with RUNX2 protein\&RNA overexpression $(p=0.01)$, aberrant $W W O X$ expression (protein\& RNA, $p=0.03)$, pTNM stage and metastasis $(p=0.026 \&$ $p=0.023$; respectively-Fig. 4). Progression free survival associated significantly with $R U N X 2$-overexpression, high pTNM stage and the incidence of metastasis $(p<0.01$ for all).

\section{Discussion}

Although the roles of WWOX and RUNX2 in OS have been previously addressed, the novelty in this work is with the assessment of these two genes in Egyptian patients who have a different ethnicity from US based patients and therefore they might show different results. Thus, this work extends the repertoire of studies on RUNX2 and WWOX in OS. We assessed the prevalence of RUNX2 and WWOX genes in conventional OS cases from Egypt and their contribution to patients' outcome. Previous studies have shown that both genes contribute to normal bone metabolism as well as to tumorigenesis and prognosis of different tumor types including OS. Thus, both genes could be used as prognostic biomarkers for OS $[6,8,9]$. The data reported in the current study show marked elevation of RUNX2 RNA and protein in OS patients compared to normal control (75 \& 90\%) whereas WWOX showed significant reduction at both the RNA and the protein levels $(80 \%)$ compared to the normal control.

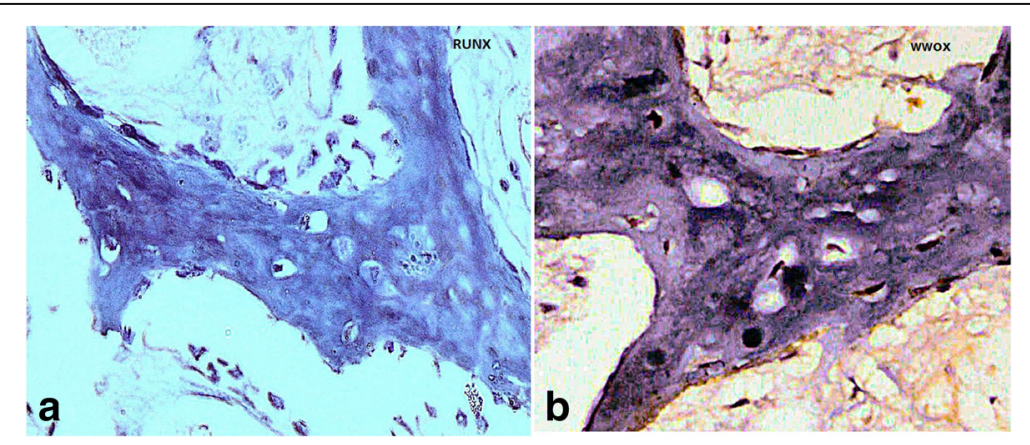

Fig. 1 Protein expression of a RUNX2 and $\mathbf{b}$ WWOX in normal boney tissues assessed by immunohistochemistry (X400) 

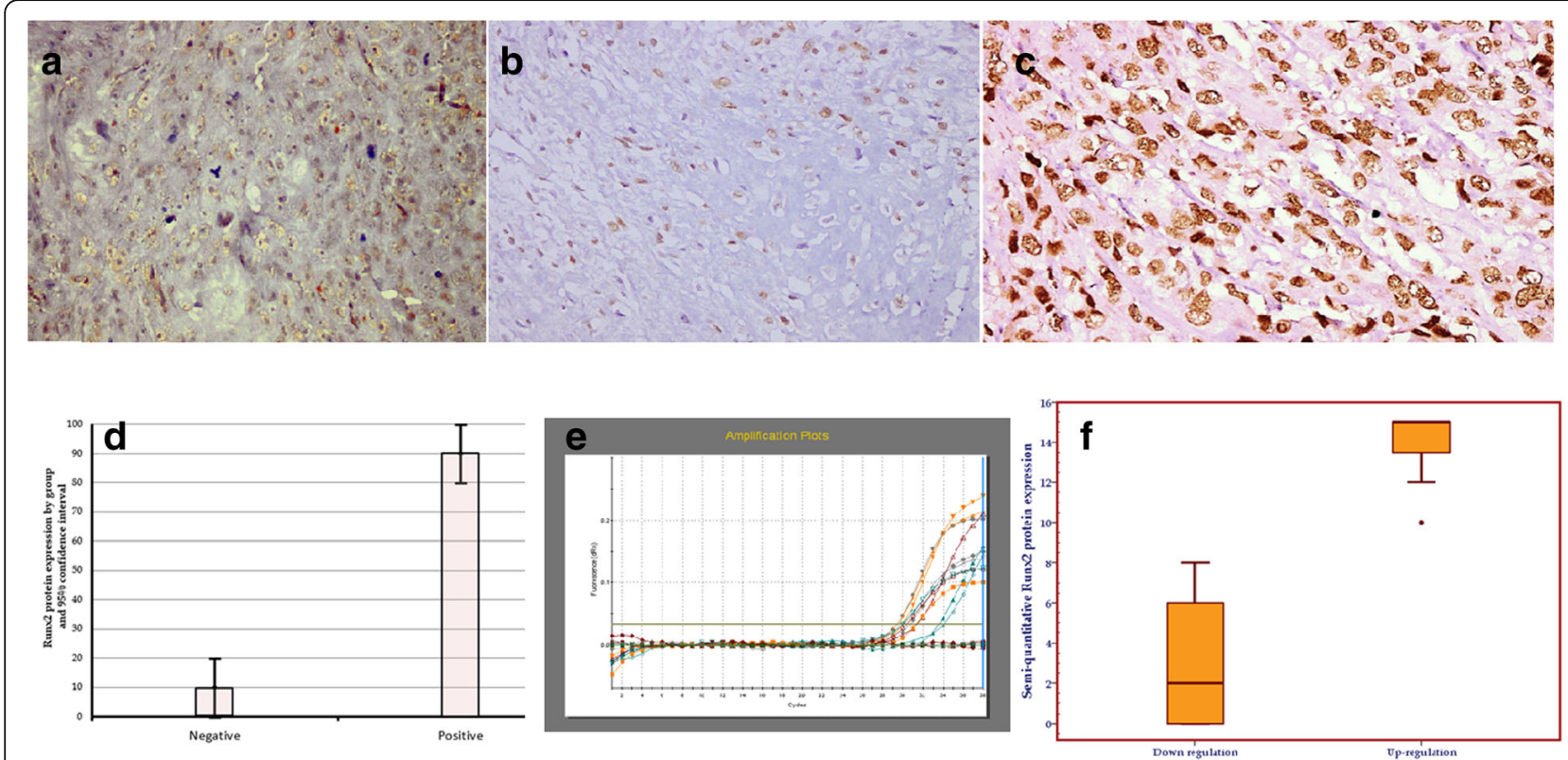

Fig. 2 Cases of osteosarcoma showing a negative immunostaining of RUNX2 in normal bony tissue (X400), $\mathbf{b}$ a case of OS, grade 2 showing moderate nuclear immunostaining of RUNX2 (X200), c a case of OS, grade 3 showing marked and diffuse nuclear immunostaining of RUNX2 (X400), $\mathbf{d}$ Bar chart showing the frequency of RUNX2 protein expression in OS cases according to groups, e Amplification plots of RUNX2, SYBR green, MAX3000P (Applied Biosystems, Inc., Foster City, CA, USA), and $\mathbf{f}$ Box blot graph showing increased RUNX2 gene and protein expressions in OS cases

Similar results have been reported in a recent study by Yang et al. [22] who found that RUNX2 protein and gene expression were increased in 48.1 and $55 \%$ of human OS cases with a significant loss of WWOX protein and DNA expressions in 61.1 and $30 \%$ of the studied cases; respectively using $\mathrm{IHC}$ and the comparative genomic hybridization $(\mathrm{GCH})$ techniques. Sadikovic et al. [24] also reported significant overexpression of RUNX2-RNA (113 folds) by quantitative real time PCR (qPCR) and Lu et al. [25] were able to detect RUNX2 RNA overexpression in
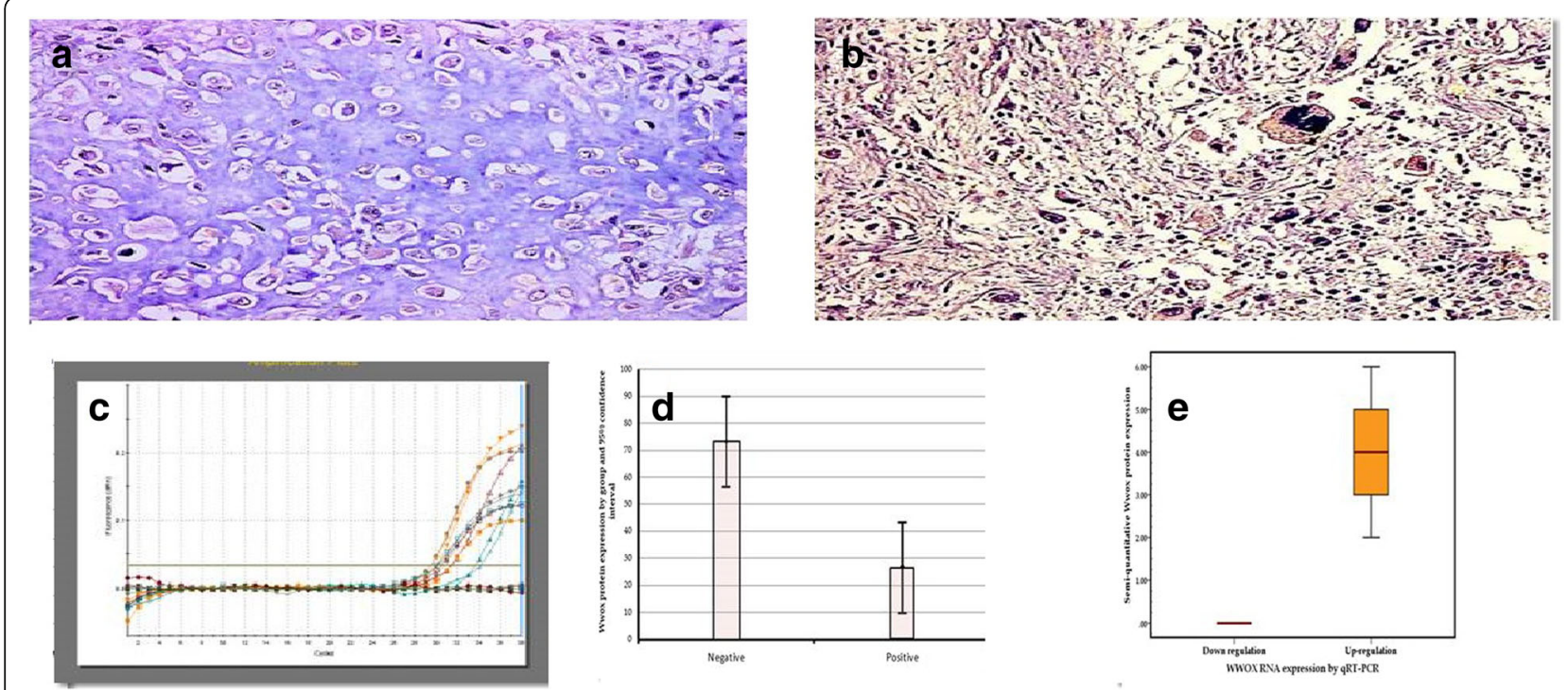

Fig. 3 Protein expression of WWOX showing a normal boney tissue showing positive WWOX immunostaining (X400), $\mathbf{b}$ a case of OS with minimal cytoplasmic WWOX expression of moderate intensity (X400), c amplification curves of WWOX, TaqMan, Rotor-gene Q (Qiagen, Hilden, Germany), d a bar chart showing the frequency of WWOX protein expression in OS cases according to groups, e Box blot graph showing decreased WWOX gene and protein expressions in OS cases 

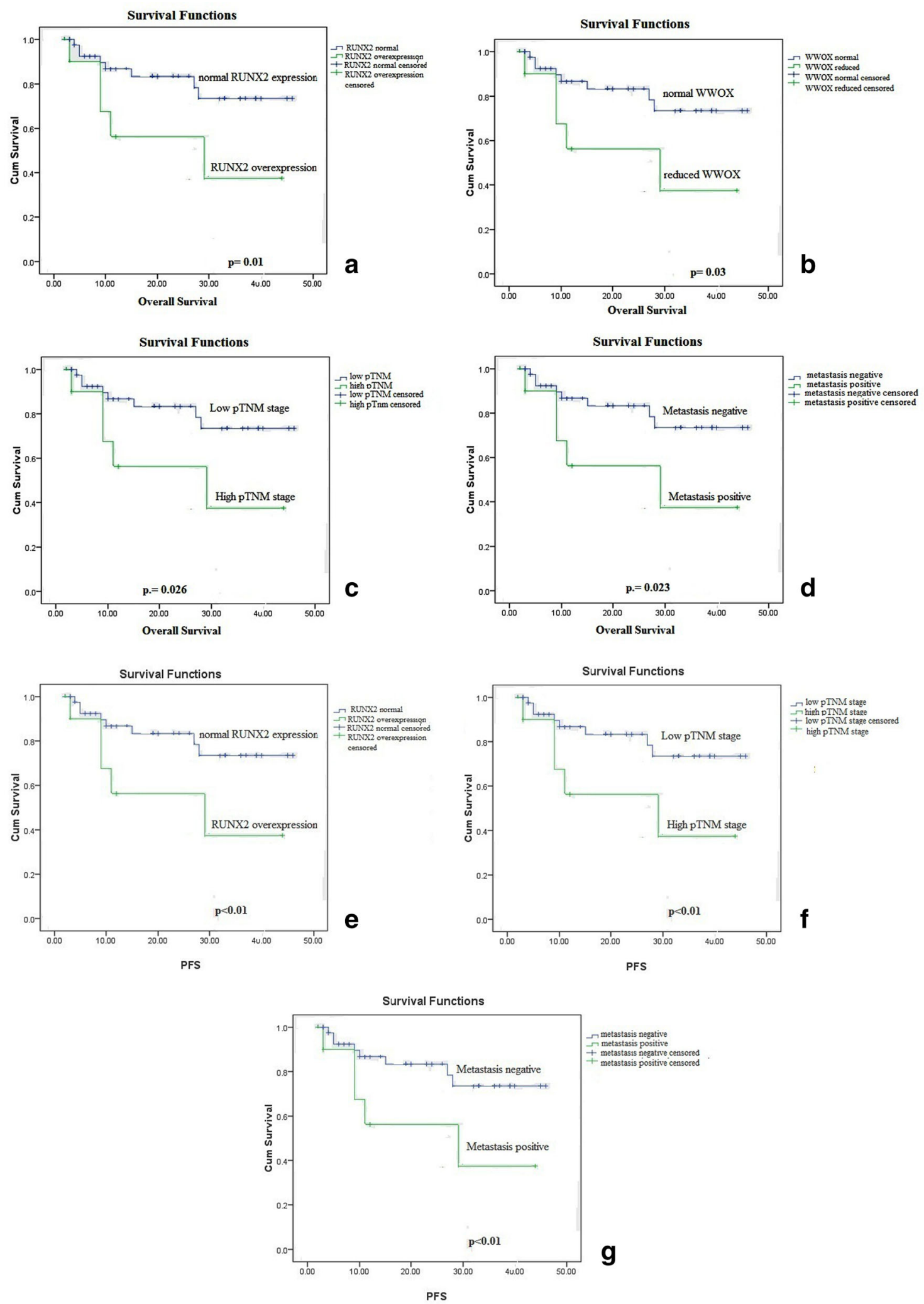

Fig. 4 Kaplan maeier curves for a OS in relation to RUNX2 expression, b OS in relation to WWOX expression, $\mathbf{c}$ OS in relation to pTNM, d OS in relation to metastasis, e PFS in relation to RUNX2 expression, $\mathbf{f}$ PFS in relation to PTNM, $\mathbf{g}$ PFS in relation to metastasis 
13 OS cell lines and in all OS tissue samples assessed in their study.

There is evidence indicating that, the normal function of RUNX2 in bone is linked to the p53-MDM2 pathway, which is perturbed in the Li-Fraumeni patients. Therefore, there is an increased incidence of $\mathrm{OS}$ in Li-Fraumeni families, which is associated with loss of $p 53$ function [26]. This loss of $p 53$ function increases the differentiationrelated accumulation of $R U N X 2$. In contrast to primary or immortalised osteoblasts, which normally have low RUNX2 levels, loss of $p 53$ correlates with elevated RUNX2 protein levels in several growth factor independent OS cell lines [26]. Hence, it is conceivable that loss of $p 53$ function in OS contributes to the elevated $p 53$ protein levels, which is observed in OS patient samples harboring 6p12-6p21 gene amplifications [26]. Therefore, we assessed our studied cases for p53 mutations (exons 4-9). Although we were able to detect some mutations in exons 5, 6 and 8; none of these mutations correlated with RUNX2 expression (data not shown). On the other hand, Kurek et al. [27] were the first to demonstrate that the WWOX gene decreases tumorigenicity in nude mice in vitro and in vivo. They found that $100 \%$ of the WWOX-deficient mice included in their study developed OS. Their data support our data in this regard.

The concordance, reported in the current study, between RUNX2 and WWOX genes expression (at the protein and RNA levels) has been previously reported by Aqeilan et al. [17] and Salah et al. [15], though other investigators failed to find any correlation between WWOX- RNA and protein in their studies $[22,27]$. This could be attributed to the presence of other factors affecting the WWOX protein expression, such as abnormal mRNA splicing, missing exon(s), loss of heterozygosity (LOH) or promotor hypermethylation of WWOX [28]. Reduced expression of WWOX was also detected in OS samples of post-treatment metastastectomies more than in the pre-treatment biopsies suggesting that decreased WWOX levels indicates more aggressive tumor phenotypes, especially in the metastatic sites [22]. Genetic and epigenetic alterations of the WWOX gene were also detected by Yang et al. [22] and Abdeen et al. [29] in the more aggressive OS cases, especially those with reduced survival rates and multiple metastases.

In accordance with these data we found that, aberrant expression levels of $W W O X$ and RUNX2 genes (RNA\& protein) were more common in patients with high grade and the advanced stage tumors, and in patients having increased incidence of metastasis. In addition aberrant expression of RUNX2 and/or WWOX proteins or RNA in our studied patients associated significantly with reduced survival rates, either OS or PFS together with the high tumor grade, advancesd disease stage and metastasis. Our data confirm previously reported data in literature regarding the prognostic and predictive values of WWOX and RUNX2 genes. It also suggests that both genes could be used as sensitive biomarkers of aggression in the conventional OS patients.

A recent in vitro and experimental animal study by Del Mare and Aqeilan, 2015 (14) provided additional evidence to the human data. In this study, the authors proved that WWOX is usually inactivated in human OS cases and its restoration in cultured $W W O X$-negative OS cells suppressed tumorigenicity and inhibited the metastatic potential in the NOD-SCID mice. They demonstrated that this is achieved either through WWOX -related down regulation of certain genes that are strongly involved in tumor cell migration and invasion e.g. ezrin, integrin alpha (4E5), $M M P 13$ and VEGF, or through suppressing RUNX2 transactivation, which normally regulates the expression of cell motility and adhesion genes in the conventional OS (14).

In the current study, we were able to show that $R U N X 2$ overexpression; either at the protein or the RNA levels; is usually associated with the aggressive tumor types providing an evidence for the prognostic value of $R U N X 2$ in conventional OS and confirming previous reports in literature in this context [24, 30-34]. In this context, Sadikovic et al. [24] demonstrated that, out of 16 genes tested in their study, RUNX2 was the only one which was significantly overexpressed in OS patients who responded poorly to chemotherapy. Similar results were also reported by Won et al. [35] who found a significant correlation between RUNX2 overexpression and the incidence of metastasis in the conventional OS. This is explainable because RUNX2 normally regulates important pathways, which are involved in cell adhesions and motility of the mobile OS cells [34]. In addition, RUNX2 stimulates VEGF promoter and consequently its protein expression, with subsequent stimulation of angiogenesis in the tumor leading to migration and metastasis of the neoplastic cells [36]. Therefore, RUNX2 and VEGF were considered by Yang et al. [22] as two synergistic molecules for angiogenesis in OS patients as well as promising candidates for targeted therapy. Taken together, these findings confirm the prognostic and predictive values of RUNX2 in the conventional OS.

\section{Conclusions}

Based on the results of the current study and the previously published data in literature, we conclude that, both the WWOX and RUNX2 genes play significant and opposing roles, in the development and progression of the conventional OS in the Egyptian patients. RUNX2 is usually overexpressed whereas $W W O X$ is usually reduced, mostly secondary to RUNX2 overexpression. Therefore both genes could be used as sensitive biomarkers in OS to predict tumor progression and patients' outcome. However, only RUNX2 could be used as a promising targeted therapy in patients who showed resistance to the traditional therapeutic modalities for OS, though this has to be tested in a future study. 


\section{Funding}

The study was funded by:

1) The National Cancer Institute, Cairo University

2) Faculty of Medicine, Alexandria University

\section{Authors' contributions}

AAB carried out and supervised the molecular genetic studies, participated in drafting the manuscript. EA participated in the design of the study and supervised the IHC. RG performed the IHC, PCR and drafted the manuscript. GEl-H revised and collected the clinical data of the patients. AA-MR: Revised and collected the clinical data of the patients. AE-B: Revised and collected the clinical data of the patients and revised the manuscript. A-RNZ: Supervised the molecular genetic studies. LKY: Designed the study and helped to draft the manuscript. All authors revised and approved the final manuscript.

\section{Competing interests}

The authors declare that they have no competing interests.

\section{Author details}

${ }^{1}$ Tissue Culture and Cytogenetics Unit, Pathology Department, National Cancer Institute, Cairo University, Fom El Khalig, Cairo 11796, Egypt. ${ }^{2}$ Pathology, Faculty of Medicine, Alexandria University, Alexandria, Egypt. ${ }^{3}$ Clinical Oncology\&Nuclear Medicine, Faculty of Medicine, Alexandria University, Alexandria, Egypt. ${ }^{4}$ Orthopedic Surgery Departments, Faculty of Medicine, Alexandria University, Faculty of Medicine, Alexandria University, Alexandria, Egypt. ${ }^{5}$ Medical Oncology, Cairo University, Cairo, Egypt. ${ }^{6}$ Cancer Biology National Cancer Institute, Cairo University, Cairo, Egypt.

\section{Received: 25 February 2016 Accepted: 25 October 2016}

\section{Published online: 08 December 2016}

\section{References}

1. Mirabello L, Troisi RJ, Savage SA. International osteosarcoma incidence patterns in children and adolescents, middle ages and elderly persons. Int J Cancer. 2009;125(1):229-34.

2. Mirabello L, Troisi RJ, Savage SA. Osteosarcoma incidence and survival rates from 1973 to 2004: data from the Surveillance, Epidemiology, and End Results Program. Cancer. 2009;115(7):1531-43.

3. Mokhtar N, Adel I. Malignant bone tumors. editors: Cancer pathology registry 2003-2004 and timed trend analysis. 2007;1st edition. Cairo: NCI Elsheraa Press (11):88-9.

4. Ando K, Heymann MF, Stresing V, Mori K, Redini F, Heymann D. Current therapeuticstrategies and novel approaches in osteosarcoma. Cancers. 2013;5(2):591-616

5. Kager L, Zoubek A, Potschger U, Kastner U, Flege S, Kempf-Bielack B, et al Primary metastatic osteosarcoma: presentation and outcome of patients treated on neoadjuvant Cooperative Osteosarcoma Study Group protocols. J Clin Oncol Off J Am Soc Clin Oncol. 2003;21(10):2011-8.

6. Jaffe N, Puri A, Gelderblom H. Osteosarcoma: evolution of treatment paradigms. Sarcoma. 2013;2013:203531.

7. Martin JW, Zielenska M, Stein GS, van Wijnen AJ, Squire JA. The Role of RUNX2 in Osteosarcoma Oncogenesis. Sarcoma. 2011;2011:282745.

8. Aqeilan RI, Croce CM. WWOX in biological control and tumorigenesis. J Cell Physiol. 2007;212(2):307-10.

9. Nathan SS, Pereira BP, Zhou YF, Gupta A, Dombrowski C, Soong R, et al. Elevated expression of Runx2 as a key parameter in the etiology of osteosarcoma. Mol Biol Rep. 2009;36(1):153-8.

10. Geoffroy $V$, Kneissel M, Fournier B, Boyde A, Matthias P. High bone resorption in adult aging transgenic mice overexpressing cbfa1/runx2 in cells of the osteoblastic lineage. Mol Cell Biol. 2002;22(17):6222-33.

11. Datta HK, Ng WF, Walker JA, Tuck SP, Varanasi SS. The cell biology of bone metabolism. J Clin Pathol. 2008;61(5):577-87

12. Sadikovic B, Yoshimoto M, Chilton-MacNeill S, Thorner P, Squire JA, Zielenska M. Identification of interactive networks of gene expression associated with osteosarcoma oncogenesis by integrated molecular profiling. Hum Mol Genet. 2009;18(11):1962-75.

13. Bednarek AK, Laflin KJ, Daniel RL, Liao Q, Hawkins KA, Aldaz CM. WWOX a novel WW domain-containing protein mapping to human chromosome 16q23.3-24.1, region frequently affected in breast cancer. Cancer Res. 2000;60(8):2140-5.
14. Del Mare S, Kurek KC, Stein GS, Lian JB, Aqeilan RI. Role of the WWOX tumor suppressor gene in bone homeostasis and the pathogenesis of osteosarcoma. Am J Cancer Res. 2011;1(5):585-94.

15. Salah Z, Ageilan R, Huebner K. WWOX gene and gene product: tumor suppression through specific protein interactions. Future Oncol (London, England). 2010;6(2):249-59.

16. Gourley C, Paige AJ, Taylor KJ, Ward C, Kuske B, Zhang J, et al. WWOX gene expression abolishes ovarian cancer tumorigenicity in vivo and decreases attachment to fibronectin via integrin alpha3. Cancer Res. 2009;69(11):4835-42.

17. Aqeilan RI, Hassan MQ, de Bruin A, Hagan JP, Volinia S, Palumbo T, et al. The WWOX tumor suppressor is essential for postnatal survival and normal bone metabolism. J Biol Chem. 2008;283(31):21629-39.

18. Abu-Odeh M, Bar-Mag T, Huang H, Kim T, Salah Z, Abdeen SK, et al. Characterizing WW Domain Interactions of Tumor Suppressor WWOX Reveals its Association with Multiprotein Networks. J Biol Chem. 2014;289(13):8865-80.

19. Aqeilan RI, Donati V, Gaudio E, Nicoloso MS, Sundvall M, Korhonen A, et al. Association of Wwox with ErbB4 in breast cancer. Cancer Res. 2007;67(19):9330-6.

20. Fletcher CDM BJ, Hogendoorn PCW, Mertens F. World Health Organization, classification of tumours: Pathology and genetics of tumors of soft tissue and bone. Lyon: IARC Press; 2013.

21. Hsu SM, Raine L, Fanger H. Use of avidin-biotin-peroxidase complex (ABC) in immunoperoxidase techniques: a comparison between $\mathrm{ABC}$ and unlabeled antibody (PAP) procedures. J Histochem Cytochem. 1981;29(4):577-80.

22. Yang J, Zhao L, Tian W, Liao Z, Zheng H, Wang G, et al. Correlation of WWOX, RUNX2 and VEGFA protein expression in human osteosarcoma. BMC Med Genet. 2013:6:56.

23. Schmittgen TD, Livak KJ. Analyzing real-time PCR data by the comparative C(T) method. Nat Protoc. 2008;3(6):1101-8.

24. Sadikovic B, Thorner P, Chilton-Macneill S, Martin JW, Cervigne NK, Squire J, et al. Expression analysis of genes associated with human osteosarcoma tumors shows correlation of RUNX2 overexpression with poor response to chemotherapy. BMC Cancer. 2010;10:202.

25. Lu XY, Lu Y, Zhao YJ, Jaeweon K, Kang J, Xiao-Nan L, et al. Cell cycle regulator gene $C D C 5 \mathrm{~L}$, a potential target for 6p12-p21 amplicon in osteosarcoma. Mol Cancer Res. 2008:6(6):937-46.

26. Martin J.W., Zielenska M., Stein G. S., vanWijnen A. J., and Squire J. A. The Role of RUNX2 in Osteosarcoma Oncogenesis. Sarcoma, Volume 2011, Article ID 282745, 13 pages doi:10.1155/2011/282745.

27. Kurek KC, Del Mare S, Salah Z, Abdeen S, Sadiq H, Lee SH, et al. Frequent attenuation of the WWOX tumor suppressor in osteosarcoma is associated with increased tumorigenicity and aberrant RUNX2 expression. Cancer Res. 2010;70(13):5577-86

28. Yang J, Cogdell D, Yang D, Hu L, Li H, Zheng H, et al. Deletion of the WWOX gene and frequent loss of its protein expression in human osteosarcoma. Cancer Lett. 2010;291(1):31-8

29. Abdeen SK, Del Mare S, Hussain S, Abu-Remaileh M, Salah Z, Hagan J, et al. Conditional inactivation of the mouse Wwox tumor suppressor gene recapitulates the null phenotype. J Cell Physiol. 2013;228(7):1377-82.

30. Li W, Xu S, Lin S, Zhao W. Overexpression of runt-related transcription factor-2 is associated with advanced tumor progression and poor prognosis in epithelial ovarian cancer. J Biomed Biotechnol. 2012;2012:456534.

31. Zhang HY, Jin L, Stilling GA, Ruebel KH, Coonse K, Tanizaki Y, et al. RUNX1 and RUNX2 upregulate Galectin-3 expression in human pituitary tumors. Endocrine. 2009:35(1):101-11.

32. Javed A, Barnes GL, Pratap J, Antkowiak T, Gerstenfeld LC, van Wijnen AJ, et al. Impaired intranuclear trafficking of Runx2 (AML3/CBFA1) transcription factors in breast cancer cells inhibits osteolysis in vivo. Proc Natl Acad Sci U S A. 2005;102(5):1454-9.

33. Tandon M, Gokul K, Ali SA, Chen Z, Lian J, Stein GS, et al. Runx2 mediates epigenetic silencing of the bone morphogenetic protein-3B (BMP-3B/GDF10) in lung cancer cells. Mol Cancer. 2012;11:27.

34. van der Deen M, Akech J, Lapointe D, Gupta S, Young DW, Montecino MA, et al. Genomic promoter occupancy of runt-related transcription factor RUNX2 in Osteosarcoma cells identifies genes involved in cell adhesion and motility. J Biol Chem. 2012;287(7):4503-17.

35. Won KY, Park HR, Park YK. Prognostic implication of immunohistochemical Runx2 expression in osteosarcoma. Tumori. 2009;95(3):311-6.

36. Lee $\mathrm{SH}$, Che $\mathrm{X}$, Jeong $\mathrm{JH}$, Choi JY, Lee $\mathrm{YJ}$, Lee $\mathrm{YH}$, et al. Runx2 protein stabilizes hypoxia-inducible factor-1alpha through competition with von Hippel-Lindau protein 20 (pVHL) and stimulates angiogenesis in growth plate hypertrophic chondrocytes. J Biol Chem. 2012;287(18):14760-71. 